\title{
Variable susceptibility and response to estrogenic chemicals in Menidia menidia
}

\author{
Tara A. Duffy*, Anne E. McElroy, David O. Conover \\ School of Marine and Atmospheric Sciences, Stony Brook University, Stony Brook, New York 11794-5000, USA
}

\begin{abstract}
Environmental endocrine disruptors can profoundly impact sex ratios of fish populations, especially if the fish exhibits plasticity in sex determination. The Atlantic silverside Menidia menidia exhibits a genetically based latitudinal cline in numerous traits including temperaturedependent sex determination (TSD), which varies from high thermal influence on sex determination in southern fish, to pure genetic sex determination (GSD), with no thermal influence in northern fish. We used this gradient in TSD/GSD to test for differential population susceptibility to a common municipal wastewater constituent, $17 \beta$-estradiol $\left(E_{2}\right)$, among 4 populations with varying levels of TSD. Larvae were exposed to $\mathrm{E}_{2}$ during sex differentiation and assessed for sex ratios. The sex ratio in southern populations was more responsive to $E_{2}$ than in northern populations, indicating differential population sensitivity. To assess the potential sensitivity of wild populations to estrogenic compounds, we measured the sex ratio in $12 \mathrm{M}$. menidia populations over a $3 \mathrm{yr}$ period along a pronounced longitudinal gradient in sewage effluent and urbanization across Long Island. Water temperatures were measured to account for thermal influence on sex ratio. We found a significant trend toward female-biased sex ratios in more urbanized estuaries, with lower proportions of females in less impacted estuaries. Temperature was ruled out as the primary cause. Because sewage effluent often carries high concentrations of estrogenic compounds, and our experiments confirmed a heightened sensitivity to $\mathrm{E}_{2}$ in fish with TSD, the most likely reason for the longitudinal trend in sex ratio is a gradient in the concentration of estrogenic compounds associated with urbanization.
\end{abstract}

KEY WORDS: Endocrine disruptor $\cdot \mathrm{TSD} \cdot \mathrm{Sex}$ ratio $\cdot$ Sex determination $\cdot 17 \beta$-estradiol

\section{INTRODUCTION}

Endocrine-disrupting chemicals (EDCs) are known to impair the fitness of freshwater fish, but impacts at the population level in marine and estuarine fish are relatively unknown (Oberdorster \& Cheek 2001, Matthiessen 2003). Included in this group are a number of organic compounds which are associated with municipal and industrial wastewater effluent and known to feminize fish in environments receiving effluent in large quantities (Sumpter 1997, 2005, Desbrow et al. 1998). Three major estrogenic compounds have been identified in sewage effluent; the natural steroids estrone $\left(E_{1}\right)$ and $17 \beta$-estradiol $\left(E_{2}\right)$, and the synthetic estrogen, $17 \alpha$-ethinylestradiol $\left(\mathrm{EE}_{2}\right)$ (Desbrow et al. 1998). Additionally, less potent, but often more con- centrated estrogenic compounds such as nonylphenol are also present in effluent (Servos et al. 2003). Routine wastewater treatment does not completely remove these compounds (Johnson \& Sumpter 2001), and urban effluents contain EDCs in concentrations reported to induce changes in behavior, growth, and reproduction of marine and freshwater fish that utilize heavily urbanized coastlines (Oberdorster \& Cheek 2001, Matthiessen 2003).

Local adaptation is well known in marine fish, and it allows populations to respond to their local environment in a way that maximizes fitness (Conover 1998, Kawecki \& Ebert 2004, Schulte 2007). Additionally, if selection acts on reproductive, metabolic, or behavioral traits to produce unique, locally adapted populations, it is likely that these populations will respond to 
EDCs in unique ways. In particular, differences in traits relating to regulation of growth, sex determination, gonad development, and reproduction in fish may be indicative of how a fish may respond to contaminants (Schulte 2007). Species that display local adaptation in traits related to sex development and maintenance may be particularly useful to determine how these traits contribute to susceptibility to contaminants that compete with reproductive hormones and disrupt endocrine function (Sumpter 1997).

Under appropriate conditions endocrine disruptors can manipulate the phenotypic sex of fish, primarily when exposed early in development (Pandian \& Sheela 1995, Strussmann \& Nakamura 2002, Mills \& Chichester 2005). Gonadal differentiation in fishes usually occurs in the late larval or early juvenile stages, when the male or female gonad develops from bi-potential germ cells (Devlin \& Nagahama 2002). Exposure to endocrine disruptors during sex differentiation can override endogenous signals, leading to skewed sex ratios. Brion et al. (2004) compared sex ratios of zebrafish Danio rerio exposed to $\mathrm{E}_{2}$ for 3 wk during 3 distinct developmental stages. The clearest shift in sex ratio to females occurred in the fish exposed prior to sex differentiation. Additionally, significant feminization of genetic males occurred when fish were exposed as juveniles, during gonadal development. Similarly, treatment of $D$. rerio with $\mathrm{EE}_{2}$, a potent synthetic estrogen, significantly biased the sex ratio toward females only when exposed during gonad differentiation (Maack \& Segner 2004). Liney et al. (2005) exposed roach Rutilus rutilus to a gradient of wastewater effluent and found little response in post-spawning males, but $100 \%$ feminization in fish exposed during the embryonic through juvenile period. Stronger responses to $\mathrm{E}_{2}$ during differentiation as compared to other developmental periods have been demonstrated in medaka Oryzias latipes (Koger et al. 2000) and the fathead minnow Pimephales promelas (van Aerle et al. 2002).

Many fish display a highly labile form of gonad differentiation known as environmental sex determination (ESD). The most prevalent form of ESD in teleosts is temperature-dependent sex determination (TSD) (Strussmann \& Nakamura 2002, Conover 2004), which Charnov \& Bull (1977) defined as the irreversible determination of sex by environmental temperature. TSD was first demonstrated as a locally adapted trait in the Atlantic silverside Menidia menidia (Atherinidae) (Conover \& Kynard 1981), and TSD has since been extensively studied in this species (Conover 1984, Conover \& Fleisher 1986, Conover \& Heins 1987). TSD is widespread, occurring in at least 54 species of fish, across 11 families (Conover 2004).

TSD reflects an increased plasticity of sex determination relative to that of a population with genetic sex determination (GSD), and small shifts in sex hormones can shift the sex of an individual with TSD (Charnov \& Bull 1977, Bulmer \& Bull 1982, Conover 2004). Therefore, fish with TSD may be more labile in their response to environmental factors during the period of sex differentiation than fish with GSD, where sex is controlled by major genetic factors. Exogenous estrogens, for example, readily feminize fish with TSD, as in the Argentinean silverside Odontesthes bonariensis when exposed during the sex determining period (Strussmann et al. 1996). In several species of turtles that possess TSD, the application of $\mathrm{E}_{2}$ during gonad differentiation causes feminization even at masculinizing temperatures (Merchant-Larios et al. 1997, Pieau \& Dorizzi 2004, Freedberg et al. 2006). To our knowledge, however, no study has compared the relative sensitivity of sex differentiation to estrogen exposure in fish with TSD versus those with GSD.

If fish with highly plastic sex determination are more sensitive to environmental endocrine disruptors, can we see these effects at the population level? While the impacts of these compounds are still relatively unknown for marine fish, skewed sex ratio and gender abnormalities have been described in numerous freshwater lake and riverine species (Mills \& Chichester 2005, Cheek 2006). Feminization is documented in populations adjacent to municipal wastewater discharge containing feminizing compounds, while fish exposed to paper mill effluent are often masculinized (Larsson et al. 2000). Evidence of endocrine disruption in the marine environment is mounting; however, many of these studies measure biomarkers of estrogenic compounds, but not the sex ratio (Oberdorster \& Cheek 2001, Mills \& Chichester 2005). Severely skewed sex ratios can often lead to a change in the reproductive capacity and therefore fitness of populations.

Here we investigated the effect of EDCs in fish populations with and without TSD. Menidia menidia was chosen as a model for this purpose because local populations differ greatly with latitude in the mode of sex determination (see above). First, we tested the hypothesis that the magnitude of the sex ratio change would be greatest in populations with TSD. To do so, we conducted laboratory experiments comparing the response in sex ratios to varying concentrations of exogenous estrogen among populations with varying levels of TSD. Second, we determined whether the sex ratio of wild $M$. menidia is correlated with an urban gradient in population density and wastewater effluents. We compared population sex ratios of $M$. menidia across a pronounced urban to non-urban gradient. We hypothesized that sex ratios in the more urbanized estuaries would be significantly more female biased than populations from estuaries receiving less wastewater discharge. 


\section{MATERIALS AND METHODS}

Study species. The Atlantic silverside Menidia menidia is one of the most common fish in the western North Atlantic, with a distribution from Volusia County, Florida, to the Magdalen Islands, Quebec, Canada (Gosline 1948, Johnson 1975). M. menidia has an annual life cycle and spawns repeatedly throughout spring and early summer. Larvae and juveniles presumably stay in natal estuaries until they are large enough to migrate in the fall (Middaugh 1981, Conover \& Ross 1982, Conover \& Kynard 1984).

Menidia menidia exhibits a latitudinal cline in the level of TSD, which is positively correlated with the length of the growing season (Conover \& Heins 1987). The level of TSD is defined as the difference in sex ratio of larval fish reared at 15 and at $28^{\circ} \mathrm{C}$ (Conover \& Heins 1987), and ranges from 0 in northern populations to 0.75 in southern populations (Duffy \& Conover unpubl. data). M. menidia at intermediate latitudes, such as New York, exhibit an intermediate level of TSD, showing partial response to temperature in addition to the contribution of genetic factors to sex ratio (Lagomarsino \& Conover 1993). A level of TSD of 0.75 indicates that a minimum of $75 \%$ of the fish have sex determination that is thermally plastic (i.e. temperature influences the phenotypic gender). Conversely, a level of TSD close to 0 is evidence that environmental temperature exerts little influence on the phenotypic sex of fish reared at temperatures that larval fish would be exposed to in nature.

TSD is adaptive for silversides that experience longer growing seasons; females are produced early, when water temperatures are lower, which gives them a size advantage over males produced later in the season. Therefore, population sex ratios are variable throughout the spawning season, reaching a balanced sex ratio at the end of the breeding season (Conover \& Kynard 1981). The latitudinal cline in TSD allows us to compare sensitivity to exogenous estrogen as a function of the level of TSD within a single species. We used 4 populations of Menidia menidia, each with different levels of TSD and GSD. A preliminary exposure of first generation $\left(\mathrm{F}_{0}\right)$ larvae from wild adults was conducted on 2 populations, and a second study using 2 laboratory-reared populations was conducted using third generation $\left(\mathrm{F}_{3}\right)$ larvae.

Experiments on $\mathbf{F}_{\mathbf{0}}$ fish. Adult Menidia menidia in spawning condition were collected in the spring of 2005 from Broad Cove, Maine, where fish were expected to have a low level of TSD $(<0.03)$ and Patchogue, New York, where fish had an expected level of TSD around 0.45 (Conover \& Heins 1987). M. menidia were strip-spawned according to Lagomarsino \& Conover (1993), and embryos were transported to Flax
Pond Laboratory in Old Field, New York. Upon hatch at $21^{\circ} \mathrm{C}$, fish $\left(\mathrm{F}_{0}\right)$ larvae were reared on Artemia sp. nauplii (Brine Shrimp Direct) in 181 containers with screens to allow water exchange with the bath in which they were submerged.

When fish reached approximately $7 \mathrm{~mm}$, they were stocked at random into closed, $12 \mathrm{l}$ containers (replicates) at a density of 60 fish container ${ }^{-1}$ with $10 \mathrm{l}$ of ambient water. This density was chosen based on previous observations of larval survival at different densities. Each treatment was carried out in 3 containers (replicates). However, a fourth control replicate was included for New York because of an excess of similar-sized larvae. Buckets were immersed in a water bath and maintained at room temperature $\left(21 \pm 0.5^{\circ} \mathrm{C}_{i}\right.$ mean \pm standard deviation, unless otherwise noted). Treatments were initiated when the average size of fish within containers reached $8 \mathrm{~mm}$ total length (TL). This size is the beginning of the thermosensitive window of sex differentiation, which occurs as fish grow from 8 to $21 \mathrm{~mm}$ TL (Conover \& Fleisher 1986). Larvae generally reached an average of $8 \mathrm{~mm}$ from 24 to $36 \mathrm{~h}$ after stocking.

Treatments of $\mathrm{E}_{2}$ (Sigma Chemical Co.) in dimethyl sulfoxide (DMSO; Baker) were added to the containers daily for a final container concentration of $100 \mathrm{ng} \mathrm{E}_{2} \mathrm{l}^{-1}$. An equal volume of DMSO without $\mathrm{E}_{2}\left(0 \mathrm{ng} \mathrm{E} \mathrm{E}^{\mathrm{l}^{-1}}\right.$, final concentration) was added to control containers. Addition of $\mathrm{E}_{2}$ mix or DMSO was carried out following daily renewal of $80 \%$ water exchange at ambient temperature. Excess food and waste were also removed daily, prior to dosing. Mortalities were noted and removed daily.

Because larval growth rates differ slightly between these populations, treatments were continued until the slower-growing (New York) population reached $21 \mathrm{~mm}$, the length at which sex is irreversibly determined (Conover \& Fleisher 1986). Thus, both populations were dosed for an equal period of $29 \mathrm{~d}$. Following the end of treatment, fish were returned to $18 \mathrm{l}$ containers and growth was allowed to occur over an additional 7 to $10 \mathrm{~d}$, to ensure all fish had reached a size at which sex could be determined by dissection. Fish were anesthetized with tricaine methane sulphonate (MS-222; Western Chemicals) and preserved in $10 \%$ sodium borate-buffered formalin (Fisher Scientific). Sex was determined with a dissecting microscope. Females were identified by the presence of large, opaque, and fragile ovaries, and males were identified by the presence of thin, translucent, flexible, and threadlike testes (Conover \& Fleisher 1986).

Experiments on $\mathbf{F}_{3}$ fish. Menidia menidia were collected from the Edisto River, South Carolina, in May 2004, and from the Annapolis River in Nova Scotia, Canada, in September 2004. These populations were 
chosen because South Carolina fish show strong thermal dependence of sex ratio, with a level of TSD around 0.7, and the Nova Scotia population displays predominantly GSD, with a level of TSD near 0 (Conover \& Heins 1987). Embryos were collected from spawning adults collected in South Carolina by stripspawning as previously mentioned and transported to Flax Pond Laboratory. Larvae were reared on Artemia sp. nauplii and were later switched to an adult diet of pellet food (Otohime Hirami), frozen brine shrimp (San Francisco Bay Brand), and frozen mysid shrimp (Hikari). Because of the time of collection, only juveniles could be collected from Nova Scotia, and these were transported to Flax Pond Laboratory and reared on the adult diet. When individuals in both populations reached sufficient size, they were induced to spawn on yarn mops with photoperiod manipulation as described by Conover \& Fleisher (1986). Third generation larvae $\left(\mathrm{F}_{3}\right)$ were collected from parents that had been held in the laboratory for 2 generations, to minimize maternal influences.

Larvae averaging 5 to $6 \mathrm{~mm}$ were randomly assigned to $12 \mathrm{l}$ containers at a density of 60 fish per $10 \mathrm{l}$ of water. For this experiment, larvae were collected from spawning adults and grouped by hatch dates within $5 \mathrm{~d}$ of each other. In the laboratory, adult Menidia menidia produced relatively low numbers of eggs over an extended period of several months (D. O. Conover pers. obs.). Therefore, it was impossible to collect enough larvae at a single time to carry out all replicates within the same period. Replicates had incomplete temporal overlap, so they were analyzed as separate trials rather than pooled for analysis. Additional treatments in this experiment necessitated the use of 2 baths for temperature control. Fish were acclimated for 48 to $72 \mathrm{~h}$ before beginning treatments, at which time the larvae averaged $8 \mathrm{~mm}$.

The $\mathrm{F}_{3}$ dosing study was carried out in a similar manner to the $\mathrm{F}_{0}$ study. A total of 4 logarithmic concentrations were chosen: 0 (control), 1 , and $10 \mathrm{ng} \mathrm{l}^{-1}$, representing measurements of $E_{2}$ in receiving waters and sewage treatment effluent (Desbrow et al. 1998, Reddy \& Brownawell 2005), and $100 \mathrm{ng} \mathrm{l}^{-1}$, representing a much higher dose than expected in nature. Each treatment received an aliquot of $\mathrm{E}_{2}$ dissolved in DMSO so that the final container concentration reflected the treatment concentration. Dosing encompassed the 8 to $21 \mathrm{~mm}$ period of sex differentiation, and was terminated after the slower growing, South Carolina population reached an average of $21 \mathrm{~mm}$ in all treatments $(34 \mathrm{~d})$. Average temperature between trials $\left(21.0 \pm 0.5^{\circ} \mathrm{C}\right)$ and between baths $\left(20.9 \pm 0.6^{\circ} \mathrm{C}\right)$ did not differ significantly ( $t$-test, $\mathrm{p}>0.05$ for both). Daily static renewal was consistent with the first experiment.

Fish were allowed to grow and depurate for 10 to $14 \mathrm{~d}$ until sizes attained were sufficient to easily assess gender, and then they were anesthetized in MS-222 and fixed in $10 \%$ buffered formalin as described above.

Field study. Long Island, New York, represents a longitudinal gradient of urbanization, with heavy municipal wastewater discharge in western estuaries adjacent to New York City, decreasing exponentially in eastern estuaries. Menidia menidia were collected annually between 2005 and 2007 from 10 sites across Long Island. For logistical reasons, some sites were replaced throughout the study period, such that a total of 12 sites were sampled over the $3 \mathrm{yr}$ period (Fig. 1).

Fish were collected using multiple tows of a 33 to $66 \mathrm{~m}$ beach seine at each site between late July and early September. Collection occurred as soon as the smallest fish in a given water body exceeded $21 \mathrm{~mm}$, which is required for accurate sex identification (Conover \& Fleisher 1986) and to ensure that all size classes were caught, minimizing gear selectivity and, thus, sex ratio bias. Collections were timed to precede size-dependent migration from estuaries, which occurs in autumn as fish become larger (Conover \& Ross 1982). Therefore, fish were presumed to have been collected in their natal estuary. Subsamples of 100 to 135 fish from each site were collected for sex identification, anesthetized with MS-222, stored on ice for transport, and then preserved in $70 \%$ ethanol.

Because temperature might explain sex ratio differences observed among sampling locations, environmental temperature was recorded throughout the summer of 2006 for all 10 sites and at 5 sites in 2007 using

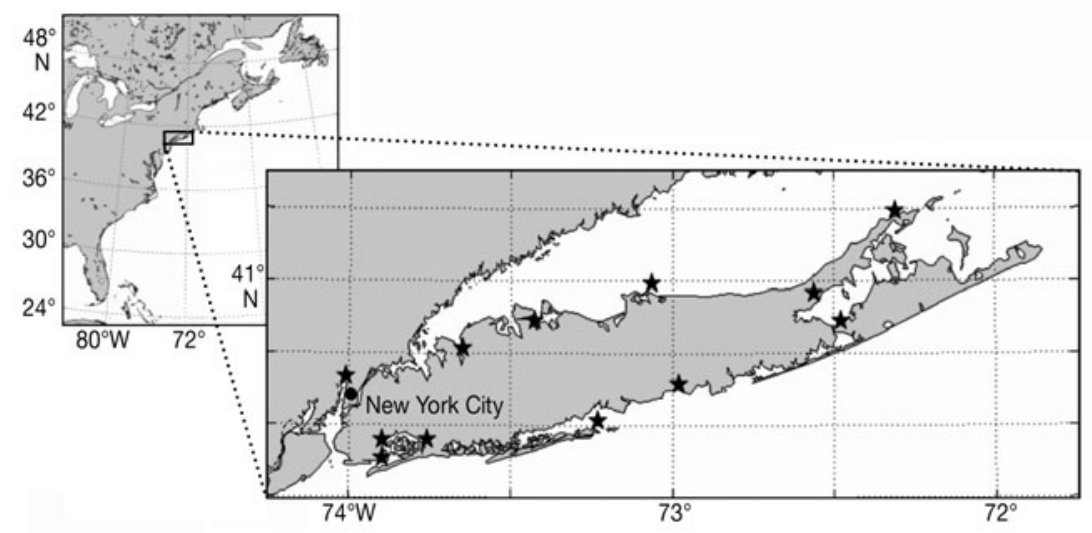

Fig. 1. Sites of Menidia menidia collection, Long Island, New York, between 2005 and 2007. Map courtesy of O. Doherty 
Hobo Pendant Temperature Loggers (Onset Computer Corp.). Loggers were placed $0.3 \mathrm{~m}$ below the lowest low water (LLW) mark for each embayment and were secured to a PVC pipe driven into the sediment. These were placed in the field between late April and early May and removed during specimen collection in late summer. Temperature was recorded 6 times daily.

Statistics. $F_{0}$ exposure: A replicated $G$-test of independence for frequency data was used to confirm that sex ratios in replicate samples were not significantly different from each other. A planned, 1-tailed G-test (Sokal \& Rohlf 1995) was then used to compare pooled treatments.

$F_{3}$ exposure: Sex ratios for individual trials were compared to the control from the same trial using a planned, 1-tailed G-test. Replicates were not combined because of incomplete temporal overlap of experimental replicates.

Field study: Sex ratio was arcsine transformed to achieve normality for all statistical tests. An ANCOVA did not reveal significant differences among the adjusted means and slopes of arcsine sex ratio regressed on longitude for 2005, 2006, and 2007 (p > 0.9) (Sokal \& Rohlf 1995). Therefore, data from 3 yr was pooled for analysis. The relationship between sex ratio and longitude was analyzed by linear regression.

Fish collected at all sites were highly variable in size $($ mean $=58.6 \pm 17 \mathrm{~mm})$, likely due to the protracted breeding season (2 mo). Therefore, fish spawned on different dates and offspring likely experienced different temperatures during the period of sex differentiation. To estimate the mean temperature that fish experienced during larval development, we assumed all fish exhibited a growth rate of $1 \mathrm{~mm} \mathrm{~d}^{-1}$ throughout the growing season based on prior studies of fish from New York (Schultz et al. 2002). Individuals were grouped by size (within $5 \mathrm{~mm}$ ), and average temperatures during the thermosensitive window for each population were calculated by using the temperature experienced by each size-class of fish and weighting this by the number of fish within each size-class. The static growth rate was used as a correction factor to determine the period of sex differentiation (8 to 21 $\mathrm{mm})$. The relationship between temperature and sex ratio was analyzed by linear regression to evaluate potential thermal influence on sex ratio.

\section{RESULTS}

\section{Experiments on $\mathrm{F}_{0}$ fish}

Sex ratios for control groups (Fig. 2) were similar to the predicted sex ratio at $21^{\circ} \mathrm{C}$ based on previous work, i.e. a sex ratio of 0.5 was expected for the Maine popu-
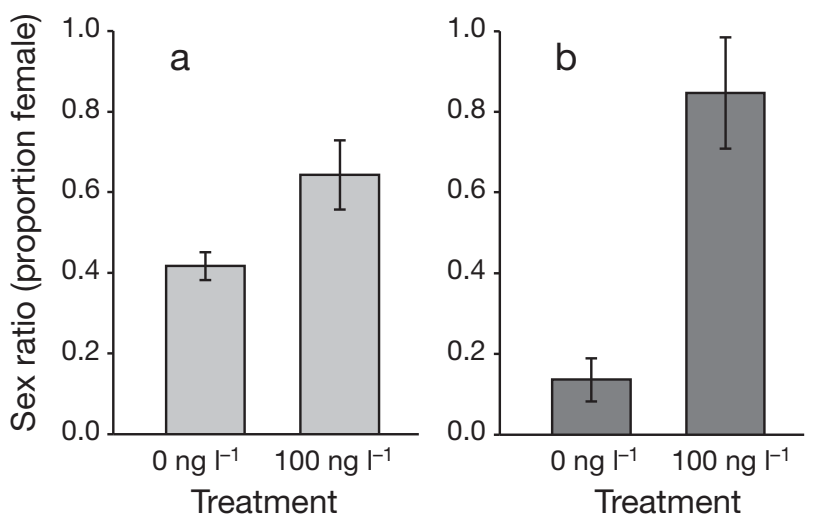

Fig. 2. Menidia menidia. Sex ratios following $17 \beta$-estradiol treatment (as proportion of females) for pooled replicates from (a) Maine and (b) New York fish (mean \pm SD). Pooled treatment replicates $\left(100 \mathrm{ng} \mathrm{l}^{-1}\right)$ are significantly different from respective controls $\left(0 \mathrm{ng} \mathrm{l}^{-1} ; \mathrm{p}<0.001\right)$ in both populations

lation, and a low proportion of females $(<0.2)$ was expected for the New York population (Conover \& Heins 1987). Both populations experienced significant $(p<0.001)$ increases in the proportion of females when dosed with $100 \mathrm{ng} \mathrm{E}_{2} \mathrm{l}^{-1}$, as compared to the control groups. However, the increase in the proportion of females was considerably smaller in the Maine population, which showed a $1.5 \times$ increase in sex ratio (Fig. 2a), as compared to the $5 \times$ increase in sex ratio in the New York population (Fig. 2b). Some mortality occurred early in each replicate, but there were no consistent differences in mortality between control and dosed groups. Average length at the end of the growout period was $39.7 \pm 4.6 \mathrm{~mm}$ for New York and $39.5 \pm$ $5.1 \mathrm{~mm}$ for Maine fish.

\section{Experiments on $F_{3}$ fish}

Both the Nova Scotia and South Carolina populations showed significant $(p<0.05)$ increases in the proportion of females in the $100 \mathrm{ng} \mathrm{l}^{-1}$ dosed group as compared to each trial's respective control (Fig. 3). The proportion of females from Nova Scotia increased significantly $(\mathrm{p}<0.05)$ in response to the $100 \mathrm{ng} \mathrm{E}_{2} \mathrm{l}^{-1}$ dose in both trials, but did not increase significantly at the lower concentrations (Fig. 3a,b).

In contrast, a significant change in sex ratio was observed with the lower concentration treatments in the fish from South Carolina. Sex ratios at 1 and 10 $\mathrm{ng} \mathrm{l}^{-1}$ were significantly different from those determined in the control $(p<0.01)$ for the first trial of South Carolina fish (Fig. 3c), and a highly significant $(p<0.001)$ increase in the proportion of females was seen after applying the $10 \mathrm{ng} \mathrm{l}^{-1}$ dose in the second trial (Fig. 3c,d). The proportion of females in the 100 

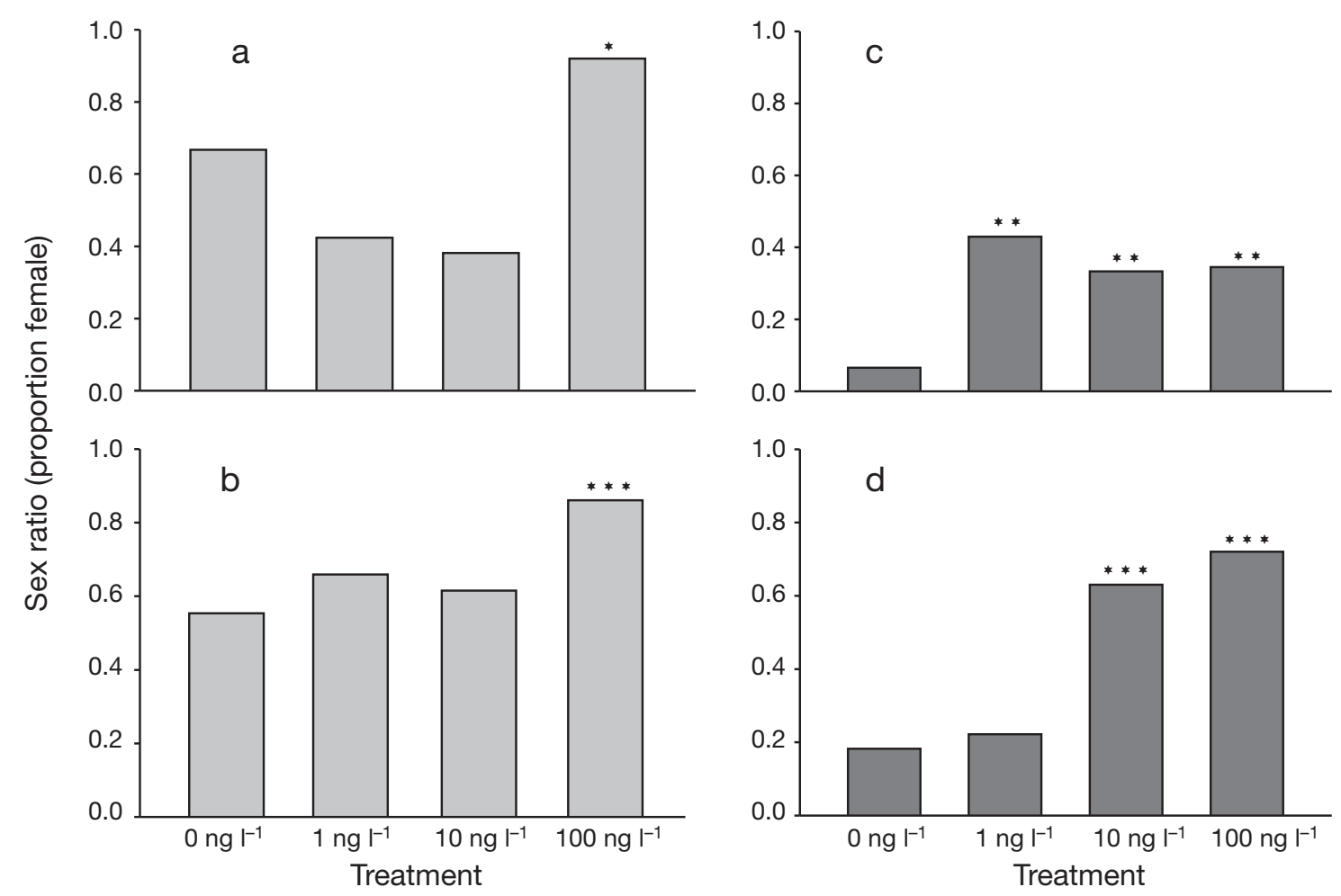

Fig. 3. Menidia menidia. Sex ratios (proportion of females) for individual F3 trials from Nova Scotia (a,b) and South Carolina (c,d). Asterisks indicate levels of significant difference compared to respective controls $\left({ }^{*} p<0.05,{ }^{* *} p<0.01,{ }^{* * *} p<0.001\right)$

ng $\mathrm{l}^{-1}$ treatment, as compared to the controls, increased substantially more in the South Carolina population (4 to $5 \times$ increase) than in the Nova Scotia population $(1.4 \times$ increase). Water temperature between trials and length of dosing period did not differ significantly. Some mortality occurred early in each trial, but there were no consistent differences in mortality between control and dosed groups. Average length at the end of the grow-out period was $25.9 \pm$ $3.9 \mathrm{~mm}$ for South Carolina and $30.3 \pm 4.2 \mathrm{~mm}$ for Nova Scotia fish.

\section{Field study}

Sex ratio was significantly correlated with longitude (Fig. $4 ; \mathrm{p}<0.001, \mathrm{r}^{2}=0.478$ ) for each year analyzed separately and for all years combined. Population sex ratios in Menidia menidia from estuaries closest to New York City were significantly more female biased than those from eastern Long Island, where the sex ratio was approximately 1:1.

Temperature was measured in the second and third year of the study to determine if the gradient in sex ratios was correlated with a gradient in temperatures across locations. No significant trend was found be- tween arcsine-transformed sex ratios and the average temperature during the thermosensitive period $\left(\mathrm{r}^{2}=\right.$ $0.03, p=0.55$ ). Additionally, a linear regression of temperature and longitude was not significant $\left(r^{2}=0.058\right.$, $\mathrm{p}>0.1)$.

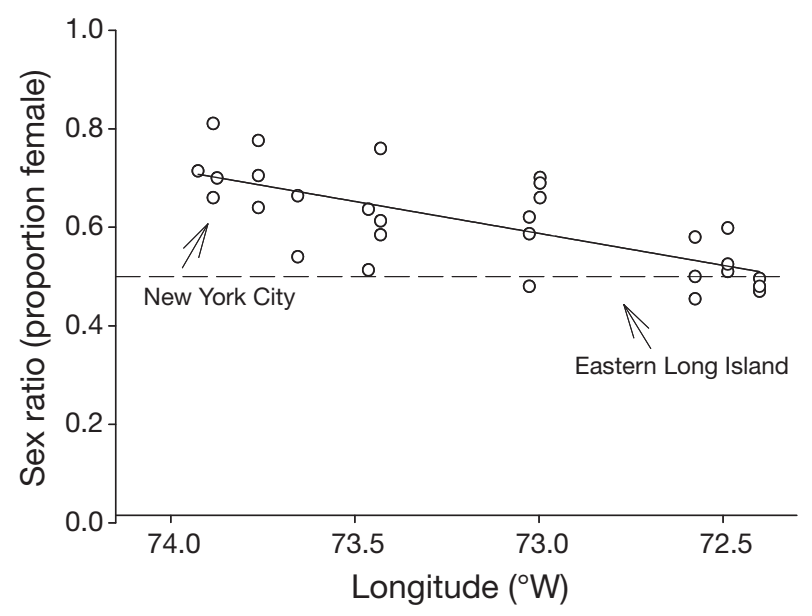

Fig. 4. Menidia menidia. Sex ratio of individuals collected along a longitudinal urban gradient $(\mathrm{p}<0.001$, adjusted $\left.r^{2}=0.478\right)$. Solid line: best-fit linear regression; dotted line: a 1:1 sex ratio 


\section{DISCUSSION}

The results from the exposure study indicate differential susceptibility to $\mathrm{E}_{2}$ among 4 populations of Menidia menidia that differ in the level of TSD. Fish from all 4 locations responded to the highest dose of $E_{2}$, with a significantly increased proportion of individuals differentiating into females. In both dosing experiments, however, southern populations exhibited the largest change in sex ratio with $\mathrm{E}_{2}$ treatment relative to northern populations. However, the magnitude of this change may be reflective of the male-biased sex ratio in the southern population control group. Nevertheless, the population from South Carolina, with the highest level of TSD, responded at lower concentrations of $E_{2}$ than did the Nova Scotia population, with complete GSD. This suggests that TSD is associated with an individual's susceptibility to $E_{2}$ exposure. This is especially likely given that the endocrine system is highly sensitive to cues from the environment during early life history (Sumpter 1997, Devlin \& Nagahama 2002, Strussmann \& Nakamura 2002). However, other intrinsic differences in the physiology of $M$. menidia could also play a role.

Fish from higher latitudes (Maine and Nova Scotia) exhibit significantly faster intrinsic growth rates than southern counterparts (Conover \& Present 1990). These genetically determined differences in growth rates are the result of differences in metabolic rates, food conversion efficiencies, and food consumption (Conover \& Present 1990, Present \& Conover 1992), and may contribute to differential response of sex differentiation to $\mathrm{E}_{2}$. Higher metabolism in northern latitude fish may mean that they are able to metabolize and remove $\mathrm{E}_{2}$ as waste in a more efficient manner than southern fish. Additionally, faster growth rates may abbreviate the window of sex differentiation, thus decreasing the period when fish may be most susceptible to $\mathrm{E}_{2}$. However, sex differentiation is known to be tightly controlled by the regulation of $\mathrm{E}_{2}$ and other steroidal hormones. The most direct and therefore parsimonious explanation is that the presence of $E_{2}$ overrode the thermal effects on sex determination (Devlin \& Nagahama 2002, Strussmann \& Nakamura 2002, Burger et al. 2007). However, indirect effects of other intrinsic characteristics that vary with latitude such as growth rate and vertebral number (Present \& Conover 1992, Billerbeck et al. 1997) cannot be ruled out.

Champlin et al. (2002) treated larval Menidia menidia collected from Rhode Island (intermediate level of TSD; T. A. Duffy \& D. O. Conover unpubl. data) with $\mathrm{E}_{2}$ for $35 \mathrm{~d}$ and found moderate to complete feminization when exposed to 10 or $50 \mathrm{ng} \mathrm{E}_{2} \mathrm{l}^{-1}$. These results are comparable to those in our study, and differences in sex ratio likely result from differences in the mode, length, and timing of exposure. Direct comparison of sex ratios from laboratory studies is difficult due to protocol differences, but the magnitude of feminization observed in $M$. menidia in response to $\mathrm{E}_{2}$ exposure is similar to that observed in other species such as Oryzias latipes (Nimrod \& Benson 1998, Koger et al. 2000).

A majority of studies that address responses of fish to EDCs reflect short-term exposure to single compounds and address changes in sex ratio, physiological and biochemical processes, and behavior (Mills \& Chichester 2005). Nash et al. (2004) compared the effect of $5 \mathrm{ng}$ $\mathrm{EE}_{2} \mathrm{l}^{-1}$ aqueous exposure on Danio rerio reproduction during a short-term (26 d) and life-long exposure. The 26 d exposure elicited no changes in egg production, viability, or embryo mortality, but the prolonged exposure resulted in $100 \%$ reproductive failure. Robinson et al. (2007) exposed the marine sand goby Pomatoschistus minutus to a range of $\mathrm{E}_{2}$ concentrations over an 8 mo period. A comparison of several indices of reproductive health such as gonadosomatic index, vitellogenin production (a biomarker of male exposure to feminizing compounds), and fertility revealed impairment to some of these parameters at intermediate concentrations (16 to $97 \mathrm{ng} \mathrm{E}_{2} \mathrm{l}^{-1}$ ) and complete reproductive failure at the highest concentration (669 $\mathrm{ng} \mathrm{E}_{2} \mathrm{l}^{-1}$ ). These studies demonstrate that exposure to EDCs in the wild have the potential to significantly alter reproductive fitness, especially for species that are exposed at critically sensitive periods or for long periods of time (Sumpter 1997, Arcand-Hoy \& Benson 1998, Oberdorster \& Cheek 2001).

Results from the field study demonstrate populationlevel differences along an urban gradient of wastewater effluent. This is evidenced by highly femalebiased Menidia menidia sex ratios from the urbanized estuaries of western Long Island compared to the approximately 1:1 sex ratios in eastern Long Island. This trend was significant in each of the 3 years sampled in the present study. Additionally, the non-significant relationship between sex ratio and temperature appeared to rule out thermal differences among estuaries as a major factor determining this pattern. Our data are consistent with the hypothesis that EDCs are sufficiently concentrated in urban estuaries to cause a sex ratio skew favoring females. This interpretation is consistent with our experimental results, and also with those on other species in which a female-biased sex ratio is a characteristic response to estrogenic compounds (Arcand-Hoy \& Benson 1998, Sumpter 2005, Cheek 2006). Further studies should explore other indices and impacts of EDCs, including biomarkers of exposure at the molecular level, reproductive impairment such as gonad pathology or fecundity, or reduced fitness in the form of diminished growth or recruitment (Mills \& Chichester 2005). 
We chose to use sex ratio as a potential indicator of estrogen and estrogen mimics because it is a simple and ecologically important population parameter in fish. The ubiquitous presence of silversides in estuaries that vary in contaminant loading, their limited movement during their larval and juvenile stages, and their presumed heightened susceptibility to endocrine disruptors during gonad differentiation makes them a good indicator species for detecting the impact of EDCs in the environment.

Human population density, and thus wastewater discharge, is markedly different between New York City and eastern Long Island. New York City (encompassing 5 counties) produces an average of 1300 million gallons $d^{-1}$ (MGD) of sewage effluent. Nassau County (immediately east of New York City) produces an average of 140 MGD, and Suffolk County (eastern half of Long Island) discharges only $30 \mathrm{MGD}$ of effluent (IEC 2008). Clostridium perfringens spores, reliable tracers of sewage effluent, demonstrate a strong positive correlation between human population density and wastewater effluent along a longitudinal gradient in Long Island Sound (Buchholtz ten Brink et al. 2000). Unfortunately, a comprehensive survey directly measuring estrogenic compounds in waters around Long Island has never been conducted, so correlation of sex ratio changes with known estrogenic sewage-derived contaminants is not possible at this time.

Previous work has demonstrated that effluent from several New York City sewage treatment plants with concentrations of $E_{1}$ and $E_{2}$ of from 5 to $13 \mathrm{ng} \mathrm{l}^{-1}$ and estrogenic nonylphenol ethoxylates is estrogenic to larval hybrid striped bass (McArdle et al. 2000, Todorov et al. 2002). Furthermore, surveys of juvenile winter flounder Pseudopleuronectes americanus have demonstrated highly female-biased sex ratios in Jamaica Bay, western Long Island, as opposed to a sex ratio of 0.5 in Shinnecock Bay off eastern Long Island (McElroy et al. 2006). Sex ratios of Menidia menidia from the present study mirror those of $P$. americanus from the same study sites. In particular, Jamaica Bay is highly urbanized and receives most of its freshwater input from wastewater (Swanson et al. 1992), and sediments contain high levels of estrogenic compounds such as $\mathrm{E}_{2}\left(<0.53 \mathrm{ng} \mathrm{g}^{-1}\right)$ and nonylphenol ethoxylates (>50 $\mathrm{\mu g} \mathrm{g}^{-1}$ ) (Ferguson et al. 2003, Reddy \& Brownawell 2005). Collectively, these studies indicate that feminization of fish in urban estuaries around New York City may be a widespread phenomenon. Although our data are consistent with the idea that environmental estrogenic chemicals play an important role in the sex ratio of $M$. menidia, more research is needed to determine the causative agent(s).

Any number of hormonal and physiological traits may contribute to population susceptibility to estro- genic chemicals (Pandian \& Sheela 1995). Kidd et al. (2007) carried out a 7 yr study by adding $E_{2}$, a more potent form of $E_{2}$ (Desbrow et al. 1998), to a lake in Canada. $\mathrm{EE}_{2}$ induced severe reproductive abnormalities in the fathead minnow Pimephales promelas, as evidenced by abnormal and arrested testicular development in males and depressed oogenesis in females. Chronic exposure resulted in reduced fecundity and an eventual population crash not seen in a nearby control lake. The authors conclude that the short lifespan of this species led to its swift collapse, relative to a healthy population of longer living pearl dace in the same lake.

Bull (1983) proposed that temperature-dependent sex determination is adaptive if the environment an individual experiences early in life disproportionately favors the fitness of one sex over the other and an individual has no control over which type of environment it enters. Endocrine disruptors in the aquatic environment may counteract the adaptive benefit of TSD by altering the sex ratio and creating individuals that are less fit in the environment, all else being equal. Hirai et al. $(2006 a, b)$ found that continuous exposure to $E_{2}$ from hatching through reproduction resulted in significantly reduced fecundity and numbers of spawning events by sex-reversed (XY) female Japanese medaka. Reproductive success of fish that are phenotypically females, but would have otherwise become a male in the absence of EDC exposure, is poorly understood and needs further evaluation to understand the response of the population as a whole. Moreover, populations with severely skewed sex ratios exhibit reduced relative fitness in the majority sex (Leimar et al. 2004), due, in part, to competition for mates (Berec \& Boukal 2004), and increased relative fitness of the minority sex. This occurs because the minority sex produces more offspring per capita than does the majority sex, and so its genes spread more quickly in subsequent generations. Because members of the minority sex are likely to possess higher levels of GSD, strong skews in sex ratio may cause the evolution of GSD over TSD (Bulmer \& Bull 1982). This process has been demonstrated through selection experiments in Menidia menidia (Conover \& Van Voorhees 1990). Hence, the sex ratio skew caused by EDCs could influence the evolution of the sex determination in populations subject to EDCs.

Our results suggest that Atlantic silversides from southern populations are especially sensitive to environmental estrogens, and they further indicate that the form of sex determination (TSD) may be a factor that contributes to this susceptibility. We have also presented evidence of population-level alteration in sex ratio in Menidia menidia in the wild, which may be attributed to a pronounced gradient of wastewater 
effluent. Because M. menidia exhibits local adaptation in TSD and GSD among populations, it represents a unique opportunity to determine how EDCs in the environment interact with the genotype of an individual to determine sex. Because TSD is common in fishes, there may be numerous other species that also possess heightened susceptibility to EDCs. Hence, an understanding of the interaction between genotypes and the environment is important in predicting the overall effect of EDCs on natural populations of fishes.

Acknowledgements. We thank L. Clarke, K. Dunton, J. Dutton, L. Hice, A. Jordaan, K. Rountos, J. Maniscalco, M. McNamara, D. Sebastiano, K. Smith, J. Socrates, G. Wagner, and C. Wall for field collection. The NY DEC provided boat time for additional collection. S. Munch provided comments on statistical analyses, and O. Doherty provided all maps. Additionally, we thank C. Knakal and S. Abrams for maintenance of fish in the laboratory. We also thank 3 anonymous reviewers for their helpful comments and suggestions. This work was funded by the Ocean Sciences Division of the National Science Foundation, Grant OCE-0425830, awarded to D.O.C. All animals used in this research were treated under the guidelines of Stony Brook University's Animal Care and Use Committee.

\section{LITERATURE CITED}

Arcand-Hoy LD, Benson WH (1998) Fish reproduction: an ecologically relevant indicator of endocrine disruption. Environ Toxicol Chem 17:49-57

Berec L, Boukal DS (2004) Implications of mate search, mate choice and divorce rate for population dynamics of sexually reproducing species. Oikos 104:122-132

Billerbeck JN, Orti G, Conover DO (1997) Latitudinal variation in vertebral number has a genetic basis in the Atlantic silverside, Menidia menidia. Can J Fish Aquat Sci 54: 1796-1801

Brion F, Tyler CR, Palazzi X, Laillet B, Porcher JM, Garric J, Flammarion P (2004) Impacts of $17 \beta$-estradiol, including environmentally relevant concentrations, on reproduction after exposure during embryo-larval-, juvenile- and adultlife stages in zebrafish (Danio rerio). Aquat Toxicol 68:193-217

Buchholtz ten Brink MR, Mecray EL, Galvin EL (2000) Clostridium perfringens in Long Island Sound sediments: an urban sedimentary record. J Coast Res 16:591-612

Bull JJ (1983) Evolution of sex determining mechanisms. Benjamin/Cummings Publishing, Menlo Park, CA

Bulmer MG, Bull JJ (1982) Models of polygenic sex determination and sex-ratio control. Evolution 36:13-26

Burger J, Fossi C, McClellan-Green P, Orlando EF (2007) Methodologies, bioindicators, and biomarkers for assessing gender-related differences in wildlife exposed to environmental chemicals. Environ Res 104:135-152

Champlin DM, Nacci DE, Serbst JR, Jayaranam S, Pelletier MC (2002) Effects of $17 \beta$-estradiol, atrazine and nonylphenol on the sex ratios of the Atlantic silverside, Menidia menidia. SETAC, 24th Annual North American Meeting, Pensacola, FL

Charnov EL, Bull J (1977) When is sex environmentally determined? Nature 266:828-830
Cheek AO (2006) Subtle sabotage: endocrine disruption in wild populations. Rev Biol Trop 54(Suppl 1):1-19

Conover DO (1984) Adaptive significance of temperaturedependent sex determination in a fish. Am Nat 123: 297-313

Conover DO (1998) Local adaptation in marine fishes: evidence and implications for stock enhancement. Bull Mar Sci 62:477-493

Conover DO (2004) Temperature dependent sex determination in fishes. In: Valenzuela N, Lance VA (eds) Temperature dependent sex determination in vertebrates. Smithsonian Books, Washington, DC, p 11-20

> Conover DO, Fleisher MH (1986) Temperature-sensitive period of sex determination in the Atlantic silverside, Menidia menidia. Can J Fish Aquat Sci 43:514-520

Conover DO, Heins SW (1987) Adaptive variation in environmental and genetic sex determination in a fish. Nature 326:496-498

Conover DO, Kynard BE (1981) Environmental sex determination-interaction of temperature and genotype in a fish. Science 213:577-579

Conover DO, Kynard BE (1984) Field and laboratory observations of spawning periodicity and behavior of a northern population of the Atlantic silverside, Menidia menidia (Pisces, Atherinidae). Environ Biol Fishes 11:161-171

Conover DO, Present TMC (1990) Countergradient variation in growth-rate - compensation for length of the growingseason among Atlantic silversides from different latitudes. Oecologia 83:316-324

> Conover DO, Ross MR (1982) Patterns in seasonal abundance, growth and biomass of the Atlantic silverside, Menidia menidia, in a New England estuary. Estuaries 5:275-286

Conover DO, Van Voorhees DA (1990) Evolution of a balanced sex-ratio by frequency-dependent selection in a fish. Science 250:1556-1558

> Desbrow C, Routledge EJ, Brighty GC, Sumpter JP, Waldock M (1998) Identification of estrogenic chemicals in STW effluent. 1. Chemical fractionation and in vitro biological screening. Environ Sci Technol 32:1549-1558

Devlin RH, Nagahama Y (2002) Sex determination and sex differentiation in fish: an overview of genetic, physiological, and environmental influences. Aquaculture 208:191-364

> Ferguson PL, Bopp RF, Chillrud SN, Aller RC, Brownawell BJ (2003) Biogeochemistry of nonylphenol ethoxylates in urban estuarine sediments. Environ Sci Technol 37: 3499-3506

> Freedberg S, Nelson CE, Ewert MA (2006) Estradiol-17ß induces lasting sex reversal at male-producing temperatures in kinosternid turtles. J Herpetol 40:95-98

Gosline WA (1948) Speciation in the fishes of the genus Menidia. Evolution 2:306-313

> Hirai N, Nanba A, Koshio M, Kondo T, Morita M, Tatarazako N (2006a) Feminization of Japanese medaka (Oryzias latipes) exposed to $17 \beta$-estradiol: effect of exposure period on spawning performance in sex-transformed females. Aquat Toxicol 79:288-295

- Hirai N, Nanba A, Koshio M, Kondo T, Morita M, Tatarazako $\mathrm{N}$ (2006b) Feminization of Japanese medaka (Oryzias latipes) exposed to $17 \beta$-estradiol: formation of testis-ova and sex-transformation during early-ontogeny. Aquat Toxicol 77:78-86

Interstate Environmental Commission (IEC) (2008) Interstate environmental commission annual report, 2007. Tri-State Water and Air Pollution Control Agency, New York

> Johnson MS (1975) Biochemical systematics of atherinid genus Menidia. Copeia 662-691

Johnson AC, Sumpter JP (2001) Removal of endocrine- 
disrupting chemicals in activated sludge treatment works. Environ Sci Technol 35:4697-4703

Kawecki TJ, Ebert D (2004) Conceptual issues in local adaptation. Ecol Lett 7:1225-1241

Kidd KA, Blanchfield PJ, Mills KH, Palace VP, Evans RE, Lazorchak JM, Flick RW (2007) Collapse of a fish population after exposure to a synthetic estrogen. Proc Natl Acad Sci USA 104:8897-8901

Koger CS, Teh SJ, Hinton DE (2000) Determining the sensitive developmental stages of intersex induction in medaka (Oryzias latipes) exposed to $17 \beta$-estradiol or testosterone. Mar Environ Res 50:201-206

Lagomarsino IV, Conover DO (1993) Variation in environmental and genotypic sex-determining mechanisms across a latitudinal gradient in the fish, Menidia menidia. Evolution 47:487-494

Larsson DGJ, Hallman H, Forlin L (2000) More male fish embryos near a pulp mill. Environ Toxicol Chem 19: 2911-2917

Leimar O, Van Dooren TJM, Hammerstein P (2004) Adaptation and constraint in the evolution of environmental sex determination. J Theor Biol 227:561-570

Liney KE, Jobling S, Shears JA, Simpson P, Tyler CR (2005) Assessing the sensitivity of different life stages for sexual disruption in roach (Rutilus rutilus) exposed to effluents from wastewater treatment works. Environ Health Perspect 113:1299-1307

Maack G, Segner H (2004) Life-stage-dependent sensitivity of zebrafish (Danio rerio) to estrogen exposure. Comp Biochem Physiol C 139:47-55

Matthiessen P (2003) Endocrine disruption in marine fish. Pure Appl Chem 75:2249-2261

McArdle M, Elskus A, McElroy A, Larsen B, Benson W, Schlenk D (2000) Estrogenic and CYP1A response of mummichogs and sunshine bass to sewage effluent. Mar Environ Res 50:175-179

McElroy A, Mena L, Taibe V, Chambers C (2006) Sediments from Jamaica Bay New York cause endocrine disruption in young-of-the-year winter flounder-nonylphenol implicated as causative agent. In: Mercaldo-Allen R, Calabrese A, Danila DJ, Dixon MS and others (eds) Proceedings of the 10th flatfish biology conference. NEFSC, Woods Hole, MA, p 31

Merchant-Larios H, Ruiz-Ramirez S, Moreno-Mendoza N, Marmolejo-Valencia A (1997) Correlation among thermosensitive period, estradiol response, and gonad differentiation in the sea turtle Lepidochelys olivacea. Gen Comp Endocrinol 107:373-385

Middaugh DP (1981) Reproductive ecology and spawning periodicity of the Atlantic silverside, Menidia menidia (Pisces, Atherinidae). Copeia 766-776

Mills LJ, Chichester C (2005) Review of evidence: Are endocrine-disrupting chemicals in the aquatic environment impacting fish populations? Sci Total Environ 343:1-34

Nash JP, Kime DE, Van der Ven LTM, Wester PW and others (2004) Long-term exposure to environmental concentrations of the pharmaceutical ethynylestradiol causes reproductive failure in fish. Environ Health Perspect 112: 1725-1733

Editorial responsibility: Hans Heinrich Janssen, Oldendorf/Luhe, Germany
Nimrod AC, Benson WH (1998) Reproduction and development of Japanese medaka following an early life stage exposure to xenoestrogens. Aquat Toxicol 44:141-156

> Oberdorster E, Cheek AO (2001) Gender benders at the beach: endocrine disruption in marine and estuarine organisms. Environ Toxicol Chem 20:23-36

> Pandian TJ, Sheela SG (1995) Hormonal induction of sex reversal in fish. Aquaculture 138:1-22

Pieau C, Dorizzi M (2004) Oestrogens and temperaturedependent sex determination in reptiles: all is in the gonads. J Endocrinol 181:367-377

> Present TMC, Conover DO (1992) Physiological-basis of latitudinal growth differences in Menidia menidia-variation in consumption or efficiency. Funct Ecol 6:23-31

Reddy S, Brownawell BJ (2005) Analysis of estrogens in sediment from a sewage-impacted urban estuary using highperformance liquid chromatography/time-of-flight mass spectrometry. Environ Toxicol Chem 24:1041-1047

Robinson CD, Brown E, Craft JA, Davies IM, Megginson C, Miller C, Moffat CF (2007) Bioindicators and reproductive effects of prolonged $17 \beta$-oestradiol exposure in a marine fish, the sand goby (Pomatoschistus minutus). Aquat Toxicol 81:397-408

Schulte PM (2007) Responses to environmental stressors in an estuarine fish: interacting stressors and the impacts of local adaptation. J Therm Biol 32:152-161

> Schultz ET, Lankford TE, Conover DO (2002) The covariance of routine and compensatory juvenile growth rates over a seasonality gradient in a coastal fish. Oecologia 133:501-509

> Servos MR, Maguire RJ, Bennie DT, Lee HB and others (2003) An ecological risk assessment of nonylphenol and its ethoxylates in the aquatic environment. Hum Ecol Risk Assess 9:569-587

Sokal RR, Rohlf FJ (1995) Biometry: the principles and practice of statistics in biological research, 3rd edn. WH Freeman \& Co, New York

Strussmann CA, Nakamura M (2002) Morphology, endocrinology, and environmental modulation of gonadal sex differentiation in teleost fishes. Fish Physiol Biochem 26: $13-29$

Strussmann CA, Takashima F, Toda K (1996) Sex differentiation and hormonal feminization in pejerrey Odontesthes bonariensis. Aquaculture 139:31-45

Sumpter JP (1997) Environmental control of fish reproduction: a different perspective. Fish Physiol Biochem 17:25-31

Sumpter JP (2005) Endocrine disrupters in the aquatic environment: an overview. Acta Hydrochim Hydrobiol 33:9-16

Swanson RL, West-Valle AS, Decker CJ (1992) Recreation vs. waste disposal: the use and management of Jamaica Bay. Long Island Hist J 5:21-41

Todorov JR, Elskus AA, Schlenk D, Ferguson PL, Brownawell BJ, McElroy AE (2002) Estrogenic responses of larval sunshine bass (Morone saxatilis $\times M$. chrysops) exposed to New York City sewage effluent. Mar Environ Res 54:691-695

van Aerle R, Pounds N, Hutchinson TH, Maddix S, Tyler CR (2002) Window of sensitivity for the estrogenic effects of ethinylestradiol in early life-stages of fathead minnow, Pimephales promelas. Ecotoxicology 11:423-434

Submitted: July 28, 2008; Accepted: January 13, 2009 Proofs received from author(s): March 27, 2009 